\title{
High Resolution in Seismic Refraction Tomography for Environmental Study
}

\author{
Andy A. Bery \\ Geophysics Section, School of Physics, Universiti Sains Malaysia, Penang, Malaysia \\ Email: andersonbery@yahoo.com.my
}

Received March 27, 2013; revised April 29, 2013; accepted May 28, 2013

Copyright (C 2013 Andy A. Bery. This is an open access article distributed under the Creative Commons Attribution License, which permits unrestricted use, distribution, and reproduction in any medium, provided the original work is properly cited.

\begin{abstract}
Seismic refraction tomography (SRT) involves more complex mathematic algorithms to fit more flexible model. In the field procedure SRT in generally needs more shot points than standard seismic refraction survey to obtain high resolution profile. In this seismic refraction study, we have used 9 shot-points for inline and 10 shot-points for offset in purpose to obtaine high resolution of seismic refraction tomography. During a recent geophysical test site, the subsurface material was mapped along survey line using seismic refraction method. Analyses of the site investigation data revealed that the studied site was made up of two layers of the subsurface. The upper layer has velocity values with range of 500 $\mathrm{m} / \mathrm{s}$ to $1500 \mathrm{~m} / \mathrm{s}$ which can be classified as unconsolidated surface deposits and mixtures of unsaturated sands and gravels. Meanwhile the lower layer has velocity values with range of $2000 \mathrm{~m} / \mathrm{s}$ to $5500 \mathrm{~m} / \mathrm{s}$ which is classified as compacted fine's soil due to high pressure of the overburden. Analysis of seismic refraction data demonstrated that refraction tomography software systems are able to reveal subsurface material which represented by their seismic velocity value. Furthermore, the velocity model obtained in this study is agreed with its synthetic modelling result as initial model. This validity and reasonable results was able to assist in interpretation of the seismic refraction method for the environmental study.
\end{abstract}

Keywords: Seismic Refraction Tomography; Seismic Velocity; Synthetic Modelling; Validity; Environmental

\section{Introduction}

The seismic refraction surveying was the first major geophysical method to be applied in the search for oil bearing structures. Today, however, oil exploration relies almost exclusively on some variety of modern reflection seismographs. Recent progress in exploration geophysics has stemmed from the computer-assisted processing and enhancement of the data interpretation. Seismic refraction surveys are still used occasionally in oil exploration, particularly where they can assist in resolving complicated problems in structural geology. Although the application of seismic refraction method in the oil industry has diminished over the years, the method has found increasing use for site investigation for civil engineering. It is a valuable investigation tool well-suited for shallow surveys, particularly when used in conjunction with the exploratory drill.

The relatively recent advent of seismic refraction tomography techniques has provided a significant new geophysical tool. Several initial studies by [1-5] indicate that refraction tomography performs well in many situations where traditional refraction techniques fail, such as velocity structures with both lateral and vertical velocity gradients. Recently, seismic refraction method has been use in environmental and engineering study. [6] presents an approach of combination of electrical resistivity and seismic refraction analysis proved that these integrated study of the physical environmental data provided a reasonable compromise between measurement time and image resolution.

Seismic refraction tomography is a geophysical method of interpreting seismic fraction data, which uses a gridded, inversion technique to determine the velocity of individual 2-dimension blocks (pixels) within a profile as opposed to modelling velocities as layers. As a result, refraction tomography can, in some cases more accurately model and provide better resolution of complex velocity structure of the subsurface. One limitation of seismic refraction is the inability to concern the existence of certain layers, referred to as hidden layers or blind zones. This is due to insufficient velocity contrast of layer thickness [7]. 
Another limitation of seismic refraction is incorrect depth calculation to certain layers where velocity reversals exist, i.e., where layer velocities do not increase with progressive depth [7]. A discussion of the strength, weaknesses and cost effectiveness of seismic refraction surveys is presented in [8].

This paper presents two examples of processing techniques for characterization of subsurface using seismic refraction. Motivation to have high resolution seismic refraction tomography, we used 9 numbers of inline shotpoint and 10 numbers of offset shot-point with 2 meter geophone interval for this environmental study.

\section{Materials and Methods}

Seismic refraction is a geophysical principle governed by Snell's Law. If a layer, in which the waves have a velocity $V_{1}$, is underlain by another layer with velocity $V_{2}$, then Snell's law can be given in Equation (1).

$$
\frac{\sin i}{\sin r}=\frac{v_{1}}{v_{2}}
$$

where, $i$ is incident angle and $r$ is refraction angle

The compressional wave that travels directly from the source to a receiver (geophones) is a body wave travelling very close to the surface. The velocity of the wave $\left(V_{1}\right)$ is the distance from the source to the receiver $(X)$ divided by the time $(t)$ it takes to travel directly to the receiver (Equation (2)).

$$
V_{1}=\frac{X}{t}
$$

The equation for the straight line represents the direct arrival on the graph travel-time (Figure 1). Therefore, Equation (2) changes to Equation (3).

$$
t=\frac{X}{v_{1}}
$$

Seismic data were recorded using a 24 channels ABEM Terraloc MK8 seismograph with 24 geophones of $14 \mathrm{~Hz}, 2$ seismic cables, a roll of trigger cable, a striker plate and $16 \mathrm{lb}$ seismic hammer to generate seismic source. In this study, we have deployed geophones with 2 $\mathrm{m}$ interval with 9 inline shot-points and 10 offset shotpoints. SeisOptim software used in this study is based upon a Monte Carlo-based optimization scheme described by [10]. For forward model, a finite-difference solution of eikonal equation [11] computes first-arrival travel times through the velocity model. Inversion is accomplished via a generalized simulated annealing global optimization algorithm. [10] demonstrates that the simulated annealing inversion algorithm is independent of the initial model. By default, a constant velocity is assigned to the model by SeisOptim to begin the optimization. Alternatively, the user can input results from a previous run as an initial model or fully specify an initial velocity model.

The synthetic model of the velocity model of the test site was carried out in this study is the result of forward modelling the seismic response of an input earth model, which in term of $2 \mathrm{D}$ variation in physical properties. This paper presents are modelling synthetic method which uses a gridded, inversion technique to determine the velocity of individual 2-dimension blocks (pixels) within a profile as opposed to modelling velocities as layers. Figure 2 shows the synthetic model of the velocity model

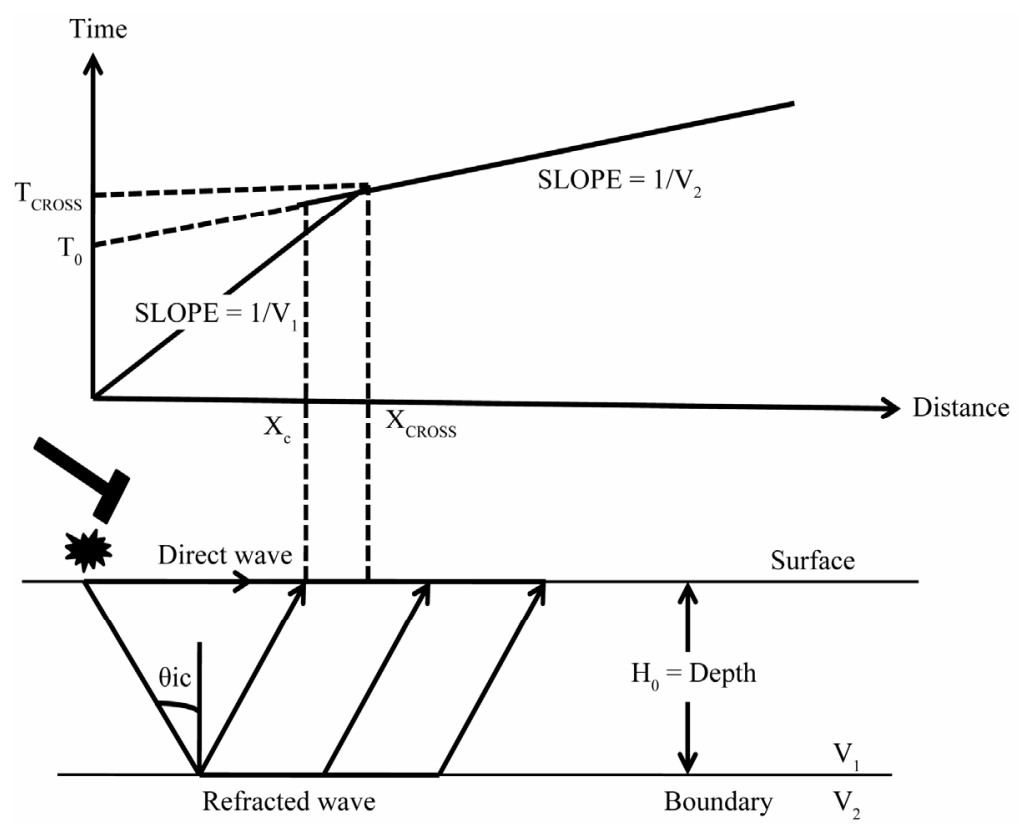

Figure 1. A schematic diagram of compressional wave and travel time curves (After: [9]). 


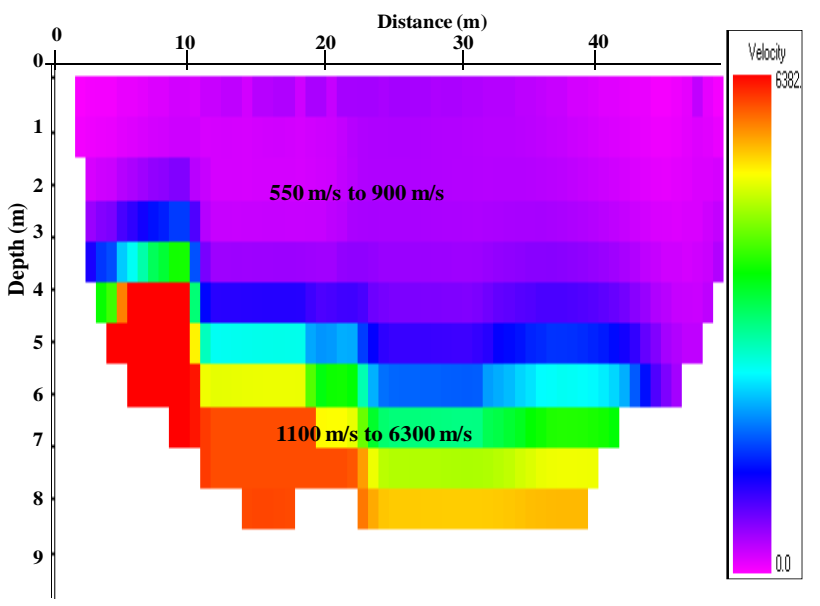

Figure 2. The synthetic velocity model for the test site.

for the test site. This approach is used to examine the seismic response of the geological section.

\section{Tomography Results and Discussion}

The seismic refraction test described above was processed by the analysis systems and P-wave velocity tomogram was produced. In order to provide uniformity to the results, tomograms from analysis system was exported to the Surfer graphical software and the data was plotted with a consistent set of special and velocity scales. By way of example, Figure 3 presents the optimum velocity tomograms for the end-to-end survey line. For each set of travel time data, multiple runs of the analysis system were conducted to exercise the model.

In this study, we show that the synthetic velocity model is nearly matched to the final result of velocity tomography model for the test site. Base on interpretation for the velocity tomography model (Figure 3), there is two main velocity layers which can be classified as layer one or upper layer and the lower layer. The upper layer has velocity values with range of $500 \mathrm{~m} / \mathrm{s}$ to $1500 \mathrm{~m} / \mathrm{s}$ which can be classified as unconsolidated surface deposits and mixtures of unsaturated sands and gravels. Meanwhile, the lower layer has velocity values with range of 2000 $\mathrm{m} / \mathrm{s}$ to $5500 \mathrm{~m} / \mathrm{s}$ which is classified as compacted fine's soil due to high pressure of the overburden.

In this study we also compared the velocity analysis using two commercially-available refraction tomography software systems to produce seismic refraction results. The second analysis scheme used in this study is FIRSTPIX V4.21 was used to pick the first arrival time and GREMIX15 software for velocity analysis and depth calculation using the Generalize Reciprocal Method (GRM). GRM calculates refractor depths for each geophone location using overlapping refraction arrival times from both forward and reverse shots, warranting multiple shots along seismic profile. Multiple numbers of shot-points along the seismic profile will permit interpretation of changing interface depths and layer velocities. The result obtains using this analysis scheme is compared with the SeisOpt software in order to verified and have reasonable interpretation for the test site. The comparison of these two tomography velocity analysis shows that there is a good correlation which the upper layer by GREMIX15 (Figure 4(b)) has velocity range within the upper layer by SeisOpt (Figure 4(a)). However, the lower layer slightly miss where GREMIX15 velocity analysis (Figure 4(b)) gives velocity range of $1300 \mathrm{~m} / \mathrm{s}$ to $3000 \mathrm{~m} / \mathrm{s}$. Whereas, the lower layer given by SeisOpt velocity analysis (Figure 4(a)) gives velocity range of $2000 \mathrm{~m} / \mathrm{s}$ to $5500 \mathrm{~m} / \mathrm{s}$.

The SeisOpt velocity models in particularly display some strange features within the lower half. These features typically occur in regions of low ray path coverage. Meanwhile the GREMIX15 velocities model unable to display the contouring such as SeisOpt velocity scheme. However, GREMIX15 velocity scheme able to give the reasonable result as SeisOpt software.

Following refraction data collection and analysis, invasive ground proving information was collected at the site to provide partial verification of the refraction test result interpretations. Soil characterizations were conducted at the test site in purpose of gain further information of the subsurface and assist in our interpretation. In this study, the moisture content, $\mathrm{W}$ (\%) and grain size analysis (gravel, sand, clay and silt) were determined in order to obtain the soil characterization of the test site. Figure 5 below shows that the variation of their values in percentage. Base on the result, it shows that they are having the same pattern for all three tested specimen. The upper layer of the test site is made up of same material.

\section{Conclusion}

Seismic refraction is a useful geophysical tool for subsurface environmental study. Initial studies by [12] and [13] indicate that seismic refraction and engineering site investigation performs well in many situations for environmental study. In this paper, the velocity structure and their depth can be estimated from the velocity analyses of seismic refraction data. Seismic refraction equipment is also portable and relatively inexpensive. Seismic refraction is also non-destructive method for environmental survey. Seismic refraction tomography is method of interpreting seismic refraction data, is well suited for subsurface investigation of areas dominated by complex shallow structure, velocity gradients and variable topography. Nonetheless of the technique used to interpret the seismic data, multiple numbers of shot-points along the survey line were able to provide greater data coverage and potentially more accurate velocity models. This paper 


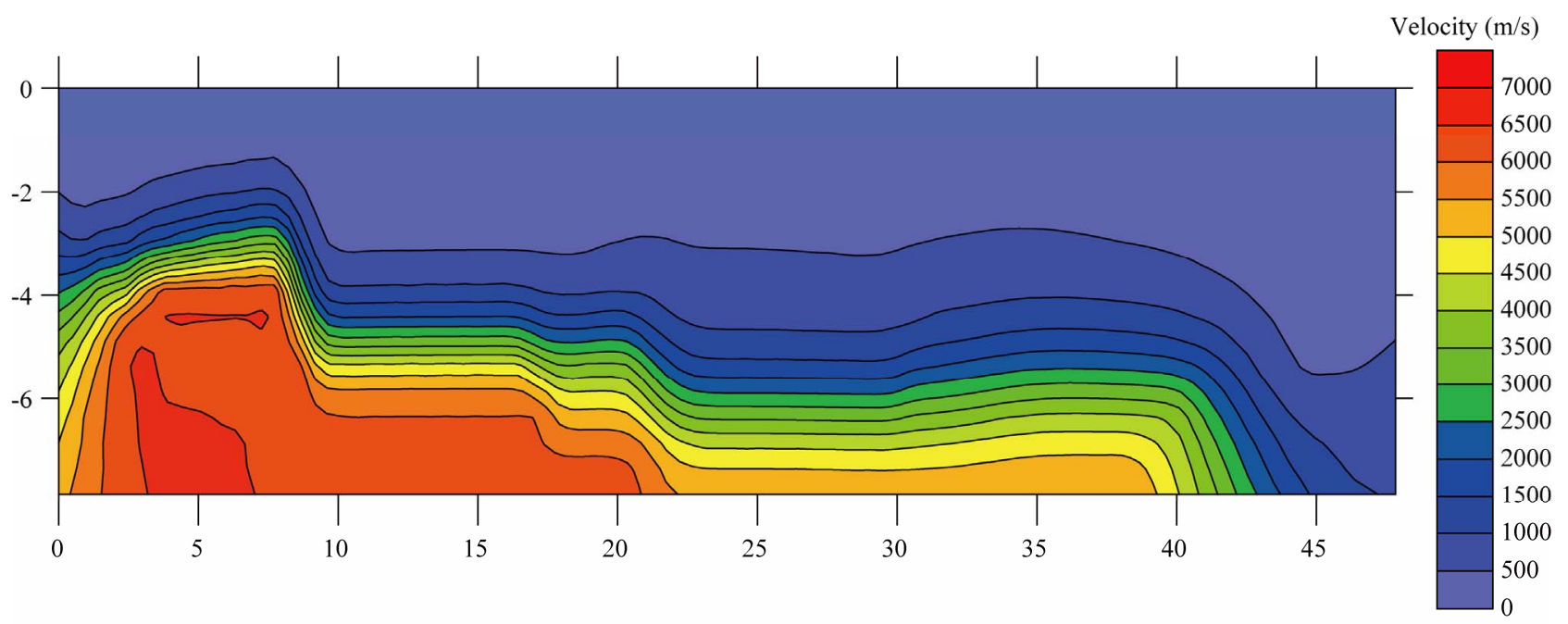

Figure 3. The velocity tomography model for the test site.

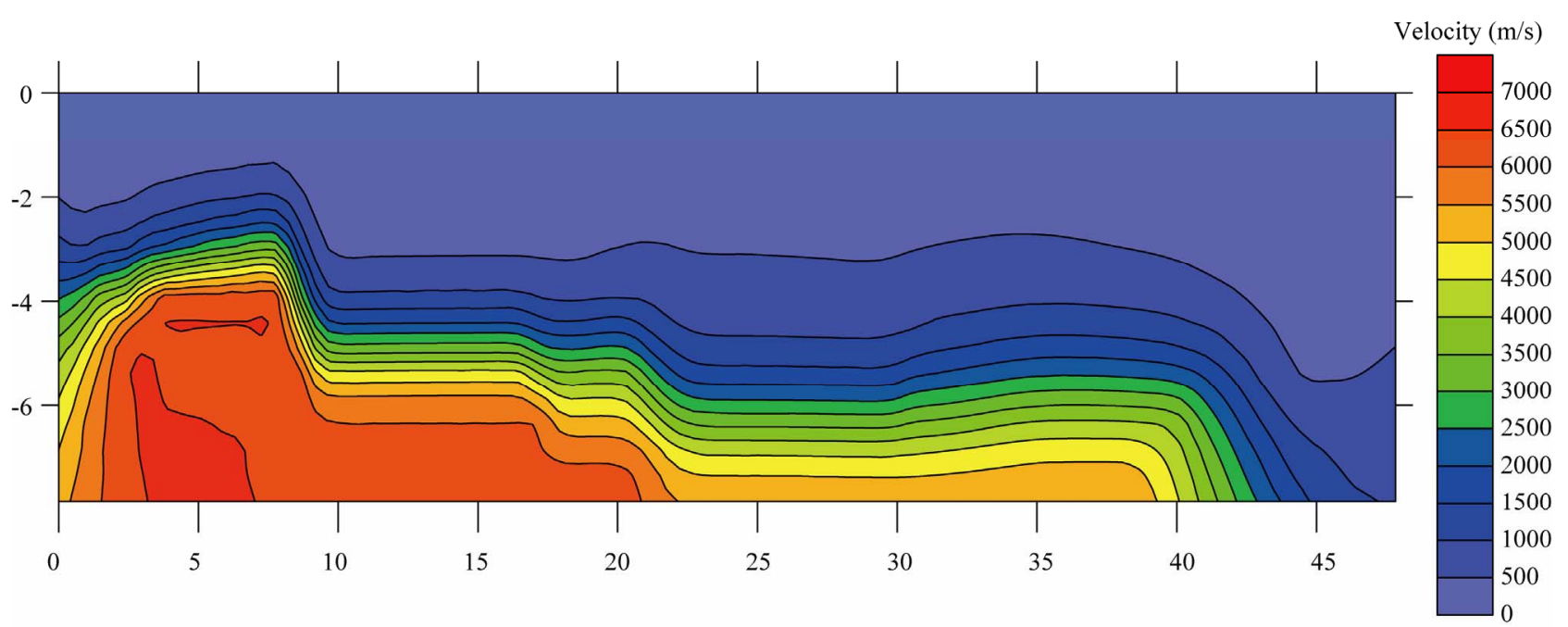

(a)

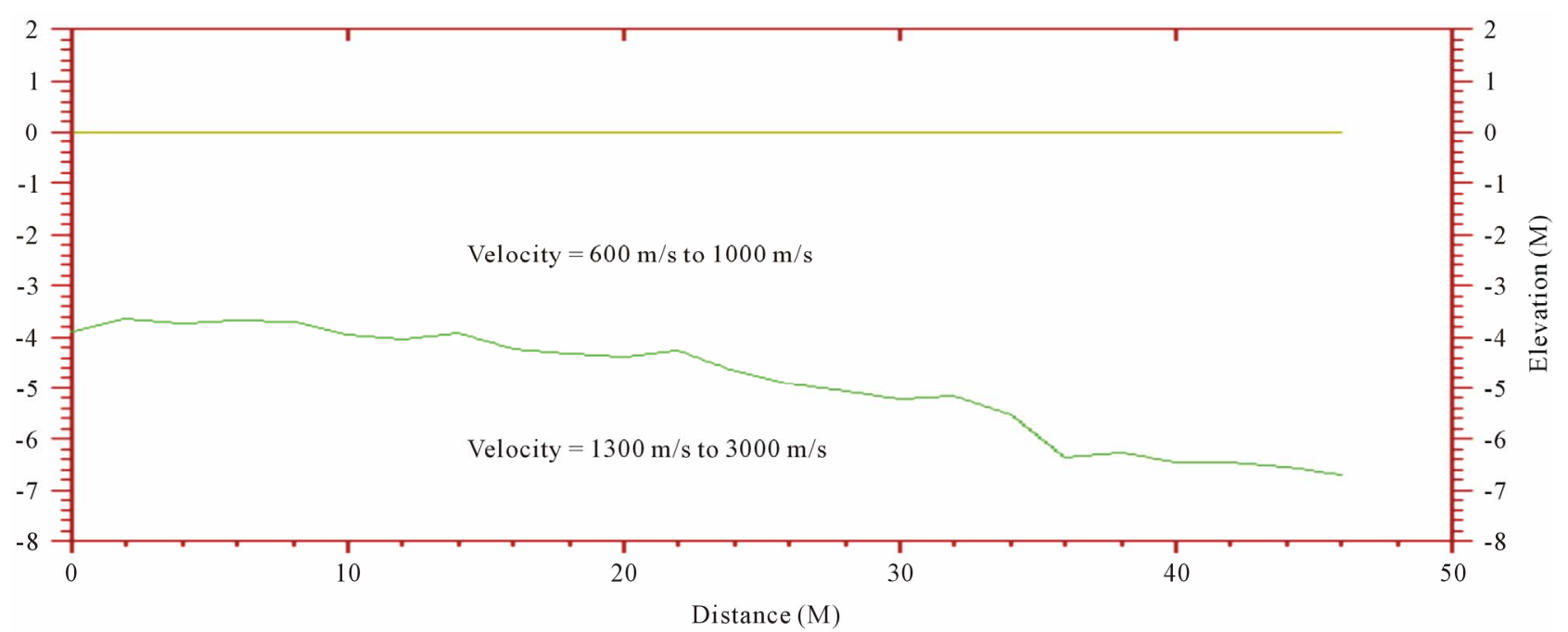

(b)

Figure 4. The comparison between the SeisOpt (a) and GREMIX15 (b) velocity model result. 


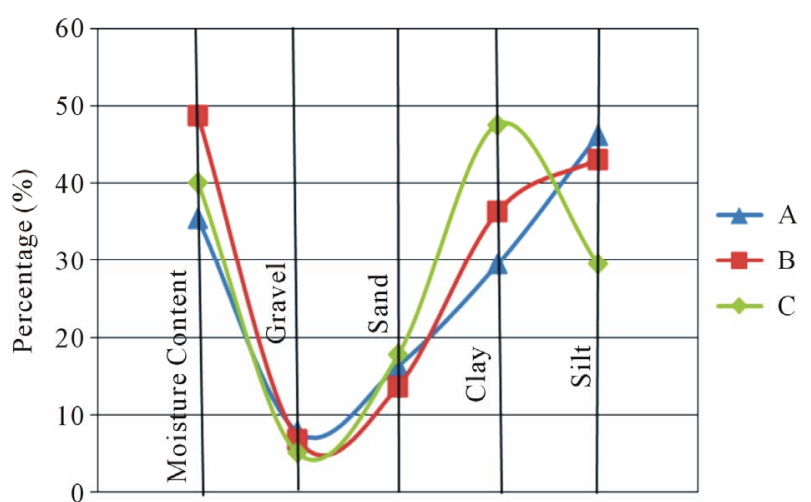

Figure 5. The variation of moisture content, gravel, sand, clay and silt values in percentage for all three tested soil specimen.

presents two examples of processing techniques for characterization of subsurface using seismic refraction. It is prudent to perform both reciprocal as well as topographic analyses as the different velocity models can complement one another and when in agreement, it able to increase confidence level in the seismic refraction interpretation.

\section{Acknowledgements}

Andy A. Bery would like to thank Rosli Saad, Yaakub Othman and I. N. Azwin for their assistance in advice and also data acquisition. Andy A. Bery also would like to wish thanks Jeff Steven and Eva Diana for their support. Lastly, the author would like to thanks and to express profound appreciation to anonymous reviewers for insightful comments that helped improved the quality of this paper.

\section{REFERENCES}

[1] P. J. Carpenter, I. C. Higuera-Diaz, M. D. Thompson, S. Atre and W. Mandell, “Accuracy of Seismic Refraction Tomography Codes at Karst Sites, Geophysical Site Characterization: Seeing beneath the Surface," Proceedings of a Symposium on the Application of Geophysics to Engineering and Environmental Problems, San Antonio, 610 April 2003, pp. 832-840.

[2] B. J. Cramer and D. R. Hiltunen, "Investigation of Bridge Foundation Sites in Karst Terrane via Seismic Refraction Tomography," 83rd Annual Meeting Compendium of Papers CD-ROM, Transportation Research Board, Washington DC, 11-15 January 2004.
[3] A. A. Bery and R. Saad, "Correlation of Seismic P-Wave Velocities with Engineering Parameters (N Value and Rock Quality) for Tropical Environmental Study,” International Journal of Geosciences, Vol. 3, No. 4, 2012, pp. 749-757. doi:10.4236/ijg.2012.34075

[4] D. R. Hiltunen and B. J. Cramer, "Geophysical Characterization of Bridge Foundation Sites in Karst Terrane," 85th Annual Meeting Compendium of Papers CD-ROM, Transpotation Research Board, Washington DC, 22-26 January 2006.

[5] J. R. Sheehan, W. E. Doll and W. A. Mandell, "An Evaluation of Methods and Available Software for Seismic Refraction Tomography Analysis,” Journal of Environmental and Engineering Geophysics, Vol. 10, No. 1, 2005, pp. 21-34. doi:10.2113/JEEG10.1.21

[6] A. A. Bery and R. Saad, “Clayey Sand Soil’s Behaviour Analysis and Imaging Subsurface Structure via Engineering Characterizations and Integrated Geophysical Tomography Modelling Methods," International Journal of Geosciences, Vol. 3, No. 1, 2012, pp. 93-104. doi:10.4236/ijg.2012.31011

[7] B. B. Redpath, "Seismic Refraction Exploration for Engineering Site Investigations,” Technical Report E-73-4, US Army Engineer Waterways Experiment Station Explosive Excavation Research Laboratory, Livermore, 1973.

[8] M. L. Rucker, "Applying the Seismic Refraction Technique to Exploration for Transportation Facilities," Geophysics 2000 Conference Proceedings, Missouri Department of Transportation, St. Louis, 2000.

[9] J. M. Reynolds, "An Introduction to Applied and Environmental Geophysics,” John Willey \& Sons Ltd., Hoboken, 1997.

[10] S. K. Pullammanappallil and J. N. Louie, “A Generalized Simulated Annealing Optimization for Inversion of FirstArrival Times," Bulletin of the Seismological Society of America, Vol. 84, No. 5, 1994, pp. 1397-1409.

[11] J. E. Vidale, "Finite Difference Calculation of Travel Times," Bulletin of the Seismological Society of America, Vol. 78, No. 6, 1988, pp. 2062-2076.

[12] A. A. Bery, "Merge-Optimization Method of Combined Tomography of Seismic Refraction and Resistivity Data," ISRN Geophysics, Vol. 2012, 2012, Article ID: 293132. doi:10.5402/2012/293132

[13] A. A. Bery and R. Saad, “Tropical Clayey Sand Soil’s Behaviour Analysis and Its Empirical Correlations via Geophysics Electrical Resistivity Method and Engineering Soil Characterizations," International Journal of Geosciences, Vol. 3, No. 1, 2012, pp. 111-116. doi:10.4236/ijg.2012.31013 